Brief article

\title{
Odors are expressible in language, as long as you speak the right language
}

\author{
Asifa Majid ${ }^{\mathrm{a}, \mathrm{c}, *}$, Niclas Burenhult ${ }^{\mathrm{b}, \mathrm{c}}$ \\ ${ }^{a}$ Centre for Language Studies and Donders Institute for Brain, Cognition and Behavior, Radboud University, Nijmegen, The Netherlands \\ ${ }^{\mathrm{b}}$ Lund University, Lund, Sweden \\ ${ }^{\mathrm{c}}$ Max Planck Institute for Psycholinguistics, Nijmegen, The Netherlands
}

\section{A R T I C L E I N F O}

\section{Article history:}

Received 12 June 2013

Revised 1 November 2013

Accepted 7 November 2013

\section{Keywords:}

Olfaction

Color

Olfactory naming

Cross-cultural

Jahai

Aslian

\begin{abstract}
A B S T R A C T
From Plato to Pinker there has been the common belief that the experience of a smell is impossible to put into words. Decades of studies have confirmed this observation. But the studies to date have focused on participants from urbanized Western societies. Cross-cultural research suggests that there may be other cultures where odors play a larger role. The Jahai of the Malay Peninsula are one such group. We tested whether Jahai speakers could name smells as easily as colors in comparison to a matched English group. Using a free naming task we show on three different measures that Jahai speakers find it as easy to name odors as colors, whereas English speakers struggle with odor naming. Our findings show that the long-held assumption that people are bad at naming smells is not universally true. Odors are expressible in language, as long as you speak the right language.
\end{abstract} (C) 2013 Elsevier B.V. All rights reserved.

\section{Introduction}

It is widely held that people find it difficult, if not impossible, to name odors. As the German physiologist and renowned olfactory specialist Hans Henning says: "olfactory abstraction is impossible. We can easily abstract the common shared color - i.e., white - of jasmine, lily-of-the-valley, camphor and milk, but no man can similarly abstract a common odor by attending to what they have in common and setting aside their differences" (Henning, 1916, p. 66). Similar sentiments have been echoed over the millennia by other renowned scholars. In a recent article, Yeshurun and Sobel (2010) on reviewing 30 years of experimental research conclude "humans are astonishingly bad at odor identification and naming" (p. 226), while Rivlin and Gravelle (1984) argue that smell

\footnotetext{
* Corresponding author. Address: Centre for Language Studies, Radboud University, P.O. Box 9103, 6500 HD Nijmegen, The Netherlands. Tel: +31(0)24361 1251 .

E-mail address: asifa.majid@let.ru.nl (A. Majid).
}

representations are simply inaccessible to the language centers of the brain (cf. Lorig, 1999).

As Henning observed, there does not seem to be a vocabulary for odors in the same league as we find for color. Words like red, blue or green denote a particular range of hues, but nothing comparable exists for scents. The closest matches stinky or fragrant appear to denote the evaluative experience of the participant rather than the quality of the smell. More importantly, people typically employ a different kind of strategy when they describe smells - they say an object smells like a banana or like a rose. That is, they identify the source that typically has that smell (Wilson \& Stevenson, 2006). Even experts in the flavor and fragrance industry primarily use source-based descriptors to refer to odors (e.g., Drake \& Civille, 2002; Zarzo, 2008), supplemented with metaphorical expressions (e.g., Caballero, 2007; Lehrer, 1983). Descriptions are often ad-hoc, and are poorly understood by non-experts (e.g., Lawless, 1984; Quandt, 2007; Solomon, 1990).

Presented with familiar everyday objects, such as coffee, peanut butter or chocolate, ordinary people correctly name 
only around 50\% of odors (Cain, 1979; Cain, de Wijk, Lulejian, Schiet, \& See, 1998; Distel \& Hudson, 2001; Lawless \& Engen, 1977). If people displayed similar performance with a visual object, they would be diagnosed as aphasic and sent for medical help. So, both in the linguistic system itself and in the everyday behavior of people we find evidence that smells are not particularly codable, or expressible, in language.

However, if we examine the data carefully we find that the majority of evidence for the poor codability of odors comes from a rather restricted source, that is, native speakers of English (and their brethren speaking related languages). Why might this be problematic? Cross-cultural investigations have demonstrated that people from Western Educated Industrialized Rich Democratic communities are outliers in their behavior - from how they perceive visual phenomena to how they reason about moral dilemmas (Henrich, Heine, \& Norenzayan, 2010). In addition, there is growing evidence that the semantic categories found in English are far from representative of the world's languages (e.g., Majid \& Levinson, 2010, 2011). There are around 6000-7000 languages spoken today, each one a solution to the communicative situation faced by speakers in different socio-cultural and ecological niches. This raises the question of whether the apparent ineffability, or inability to put words to smells, is really telling us something about all of humanity, or something specific about speakers of English (cf. Levinson \& Majid, in press).

In fact, there are plenty of indications in the literature that odors figure prominently in other cultures (Classen, Howes, \& Synnott, 1994; Hombert, 1992; van Beek, 1992). Hidden in the literature are reports of elaborate odor lexicons. One of the earliest is a brief 2-page report by Aschmann (1946) on the smell terms of Totonac (Totonacan; Mexico). The Aslian (Austroasiatic) languages of the Malay Peninsula, Southeast Asia, also boast such odor lexicons (Burenhult \& Majid, 2011; Tufvesson, 2011; Wnuk \& Majid, 2012). Jahai is one of these languages. The Jahai, a group of nomadic hunter-gatherers in the mountain rainforests along the border between Peninsular Malaysia and Thailand, have a lexicon of over a dozen verbs of olfaction that are used to describe a wide array of odors. These are "basic" smell words (cf. Berlin \& Kay, 1969): they are monolexemic and psychologically salient; they are not source-descriptors, nor are they restricted to a narrow class of objects (Burenhult \& Majid, 2011). For example, the term ltpit is used to describe the smell of various flowers and ripe fruit, including intense smell of durian, perfume, soap, Aquillaria wood, and bearcat (Arctictis binturong, which, according to Wikipedia, smells like popcorn). C $\varepsilon \varepsilon s$, another smell word, is used for the smell of petrol, smoke, bat droppings and bat caves, some species of millipede, root of wild ginger, leaf of gingerwort, wood of wild mango, among other odor sources. So, these terms refer to different odor qualities.

On the surface languages like Jahai challenge Henning's claim that olfactory abstraction is impossible. To date, however, there has been no systematic experimental test of whether odors are easy to describe by speakers with a specialized olfactory lexicon. Although such languages provide speakers with a rich set of olfactory words, perhaps speakers still struggle to use them with ease. If so, then Jahai speakers would find it as difficult to name smells as English speakers when tested under controlled conditions.

To test this we presented Jahai speakers with the Brief Smell Identification Test (B-SIT) ${ }^{\mathrm{TM}}$ (Doty, Shaman, \& Dann, 1984), and compared their naming behavior to age- and gender-matched English speakers. The B-SIT is designed to be run as a forced multiple-choice; however, that is obviously not appropriate to our goals as we are interested in eliciting Jahai smell words. So, the B-SIT was used in a free-naming paradigm instead. We also elicited free-naming to color stimuli, using Munsell color chips, to provide a further point of comparison. Speakers were asked in their native language to name stimuli one at a time and we measured the "codability" of color and smell. Drawing on Brown and Lenneberg (1954), we operationalized codability in three ways: (1) speaker agreement in descriptions, (2) length of utterance, and (3) type of response offered (abstract, source-based, or evaluative). If cultures differ in the ease with which odors are expressed in language, then we would expect to find an interaction between language and sensory domain. If, on the other hand, odors are universally ineffable we would not expect an interaction, only a main effect of sensory domain.

\section{Methods}

\subsection{Participants}

Participants were 10 native speakers of Jahai, all men, with a mean age of 37 years (range 20-60 years). They were tested in the resettlement village of Air Banun, Hulu Perak district, Peninsular Malaysia. Three had basic schooling (1-3 years primary school in Malay; all Jahai speak Malay as a second language); only one could be considered fully literate. Although mostly resident in a resettlement village with frequent exposure to modernity, all participants still pursue traditional foraging as their primary livelihood.

Ten speakers of American English were matched to the Jahai; all were men, mean age 42 years (range 28-56). There was no difference between age groups $t(18)=1.02$, $p=.32$. English participants were tested in Austin, Texas. Most had some knowledge of Spanish, but only one participant was proficient in a second language, and that same participant had a university education. All other participants had at most a high school education. All Jahai participants were smokers but only four English speakers smoked. Everyone was screened for color blindness using Ishihara plates.

\subsection{Stimuli}

For the odor task, The Brief Smell Identification Test ${ }^{\mathrm{TM}}$ (Doty et al., 1984) was used. Odorants are microencapsulated and the odor is released by scratching a card with a pencil. The 12 odorants in the test were administered to participants in a fixed order: cinnamon, turpentine, lemon, smoke, chocolate, rose, paint thinner, banana, pineapple, gasoline, soap, and onion. 
For the color task, participants saw 80 Munsell color chips, sampling 20 equally spaced hues at 4 degrees of brightness. Colors were presented in a randomized fixed order. After the free naming task, participants were shown a sheet with all 80 color chips laid out according to hue and brightness, plus 4 additional achromatic colors, and asked to identify the best example of the most frequent colors elicited from the naming task.

\subsection{Procedure}

Participants were tested in their native language, i.e., English and Jahai. For the smell task participants were asked "What smell is this?"; in Jahai mey mni? ?o? tõ $h$ (literally: what smell 3S DEM 'what smell this one'). For the color task, participants were asked "What color is this?"; in Jahai mey warnəh ?o? tõh (literally: what color 3S DEM 'what color this one'). Participants completed the color task first.

\section{Results}

Free responses can be variable because participants use hedges and modifiers, for example, quite red, very red, pinkish red, etc. Although each response is distinct, speakers clearly agree on the color name red. So we calculated rate of agreement on the main response (e.g., red) using Simpson's Diversity Index (Simpson, 1949), calculated using $D=\sum n(n-1) / N(N-1)$, where $n=$ the total number of responses using that particular name and $N=$ the total number of responses across all names. Simpson's Diversity Index provides a summary statistic that takes into account the number of different words produced, as well as how often each word appeared. Zero indicates each participant gave a unique response for a stimulus, while 1 indicates all participants agreed and the same word was used by all.

We analyzed codability scores across items, using a 2-by-2 ANOVA, treating language as a within-items factor and sensory domain as a between-items factor. Participants sometimes gave multiple responses for the same stimulus (see below). We began by analyzing agreement on first responses, as these can be taken to be the most salient linguistic responses. The raw Simpson's Diversity Index scores were not normally distributed, and so were log-transformed. The results show odors are not universally ineffable. There was an interaction between language and domain $F(1,90)=88.47, p<.0001, n_{p}^{2}=.50$. Odors are as codable as colors in Jahai $F(1,90)=.001, p=.97, n_{p}^{2}=.00$, but they are significantly less codable than colors in English $F(1,90)=205.96, p<.0001, n_{p}^{2}=.70$ (see Fig. 1). Odors were also more codable in Jahai than English $F(1,90)=51.7, p<0001, n_{p}^{2}=.37$; but colors were more codable in English $F(1,90)=55.92, p<.0001, n_{p}^{2}=.38$ (see Fig. 2). The Jahai color categories are different to those in English, but are nevertheless coherent groupings consistent with those found in other non-literate languages (Regier, Kay, \& Cook, 2005). There were also main effects of language $F(1,90)=16.03, p<.0001, n_{p}^{2}=.15$ and domain $F(1,90)=112.56, p<.0001, n_{p}^{2}=.56$.

English speakers' first responses showed very low agreement for odors. However, they often offered multiple responses for the same stimulus. For example, for the cinnamon stimulus one English speaker said: "I don't know how to say that, sweet, yeah; I have tasted that gum like Big Red or something tastes like, what do I want to say? I can't get the word. Jesus it's like that gum smell like something like Big Red. Can I say that? Ok. Big Red. Big Red gum". This response includes 3 different odor descriptions: sweet, gum, and Big Red. Would English speakers show a different pattern if we took all these responses into consideration? The answer is no. We re-calculated Simpson's Diversity Index taking all responses into consideration, and there remained an interaction between language and domain $F(1,90)=$ 24.86, $p<.0001, n_{p}^{2}=.22$, with no difference between odors and colors in Jahai $F(1,90)=.06, p=.81, n_{p}^{2}=.00$ but significantly higher codability for colors than odors in English $F(1,90)=42.67, p<.0001, n_{p}^{2}=.32$. As before, odors were more codable in Jahai than English $F(1,90)=21.88, \quad p<0001, n_{p}^{2}=.20$; colors were more codable in English $F(1,90)=76.03, p<.0001, n_{p}^{2}=.46$.

Next we compared length of description: more succinct descriptions indicate higher codability, whereas long, elaborate descriptions indicate the person is struggling to put thoughts into words (Brown \& Lenneberg, 1954). Separate participant- and item-analyses on length of description (in number of letters) revealed once again an interaction between language and domain $F_{1}(1,18)=$ $20.62, p<.0001, n_{p}^{2}=.53 ; \quad F_{2}(1,90)=590.14, p<.0001$, $n_{p}^{2}=.87$. Color descriptions were marginally longer $(M=4.91)$ than odor descriptions in Jahai $(M=4.63)$ $F_{1}(1,18)=.001, p=.97, n_{p}^{2}=.00 ; F_{2}(1,90)=7.26, p<.008$, $n_{p}^{2}=.08$. But odor descriptions were significantly longer $(M=65.93)$ than color descriptions in English $(M=14.46)$ $F_{1}(1,18)=40.80, \quad p<.0001, \quad n_{p}^{2}=.69 ; \quad F_{2}(1,90)=584.75$, $p<.0001, n_{p}^{2}=.87$. In fact, English responses for odors are

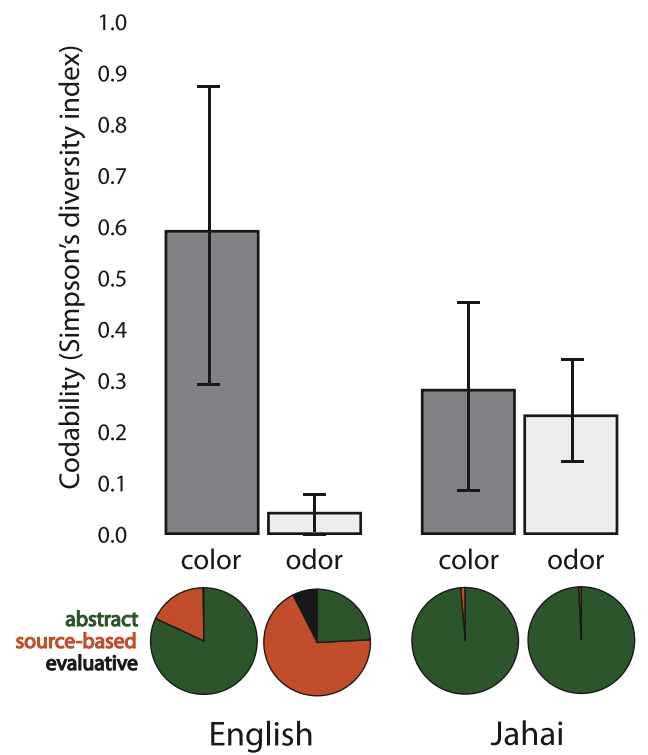

Fig. 1. English speakers show poor codability for odors in comparison to color, thus replicating previous studies. They use predominantly source-based descriptions for odors, but abstract descriptions for colors. Jahai speakers show equal codability for odors and colors, using abstract terms for both. (For interpretation of the references to color in this figure legend, the reader is referred to the web version of this article.) 
Jahai

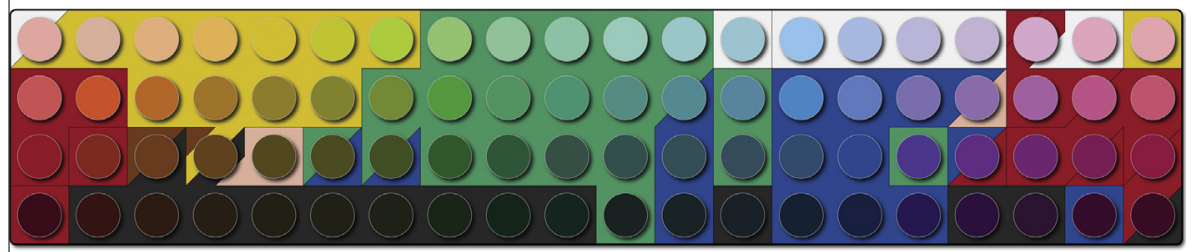

English

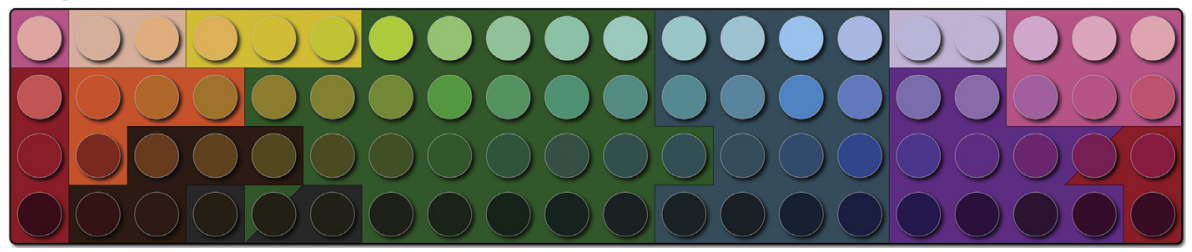

Fig. 2. English and Jahai color maps. The maps show the range of chips called by the same term in each language, with the background color depicting the best exemplar of each language's terms. (For interpretation of the references to color in this figure legend, the reader is referred to the web version of this article.)

Table 1

Jahai odor and color terms. A list of the Jahai odor terms are given. Not all of these were attested in the experimental task. The color terms listed were dominant for at least one color chip in the color naming task, unless otherwise indicated. Glosses are based on a separate focal color elicitation task.

\begin{tabular}{|c|c|c|c|}
\hline $\begin{array}{l}\text { Odor } \\
\text { terms }\end{array}$ & Approximate translation & $\begin{array}{l}\text { Color } \\
\text { terms }\end{array}$ & Approximate translation \\
\hline chos & 'to smell edible, tasty’ e.g., cooked food, sweets & byok & 'to be white' (not a dominant response) \\
\hline crijir & 'to smell roasted' e.g., roasted food & gcĩh & 'to be black' \\
\hline harim & $\begin{array}{l}\text { 'to be fragrant' e.g., various species of flowers, perfumes, } \\
\text { soap (Malay loan; original Malay meaning 'fragrant') }\end{array}$ & rhik & 'to be red' \\
\hline ltpit & 'to be fragrant' e.g., various flowers, perfumes, bearcat & rgəy & 'to be red' \\
\hline$h a ? \tilde{\varepsilon} t$ & 'to stink' e.g., feces, rotten meat, prawn paste & bkup & 'to be beige' \\
\hline$p^{?} u s$ & ‘to be musty' e.g., old dwellings, mushrooms, stale food & puteh & 'to be white' (Malay loan; original Malay meaning 'white') \\
\hline çes & 'to have a stinging smell' e.g., petrol, smoke, bat droppings & merah & 'to be red' (Malay loan; original Malay meaning 'red') \\
\hline$s \tilde{\imath} \eta$ & $\begin{array}{l}\text { 'to have a smell of human urine' e.g., human urine, } \\
\text { village ground }\end{array}$ & klabu? & $\begin{array}{l}\text { 'to be grey' (Malay loan; original Malay meaning 'grey, } \\
\text { ash-colored') }\end{array}$ \\
\hline hapcĩ $\eta$ & $\begin{array}{l}\text { 'to have a urine-like smell' e.g., urine (Malay loan; original } \\
\text { Malay meaning 'foul odor, stench') }\end{array}$ & hijow & 'to be grue' (Malay loan; original Malay meaning 'green') \\
\hline p?ih & $\begin{array}{l}\text { 'to have a blood/fish/meat-like smell' e.g., blood, raw fish, } \\
\text { raw meat }\end{array}$ & biruh & 'to be blue' (Malay loan; original Malay meaning ‘blue’) \\
\hline pl?ey & $\begin{array}{l}\text { 'to have a blood/fish/meat-like smell' e.g., blood, raw fish, } \\
\text { raw meat }\end{array}$ & meloh & $\begin{array}{l}\text { 'to be brown' (Malay loan; source-based term; original } \\
\text { Malay meaning 'milo-colored', 'brown') }\end{array}$ \\
\hline$p l>\varepsilon \eta$ & $\begin{array}{l}\text { 'to have a bloody smell which attracts tigers' e.g., crushed } \\
\text { head lice, squirrel blood }\end{array}$ & kunin & 'to be yellow' (Malay loan; original Malay meaning ‘yellow') \\
\hline
\end{tabular}

nearly 5 times longer than for color. This pattern confirms English speakers - unlike Jahai speakers - find odors more difficult to describe than colors.

Finally, we examined types of responses for each domain, distinguishing whether it was abstract (e.g., blue, musty), ${ }_{1}^{1}$ source-based (e.g., leaf-colored, like a banana), or evaluative (e.g., nice, disgusting). There was a strikingly different coding strategy by language and domain. Jahai speakers produced abstract words $99 \%$ of the time for both odors and colors, and there was no statistical difference

\footnotetext{
${ }^{1}$ For English odor descriptions, we generously coded as abstract derived adjectives ending with the suffix $-y$ (e.g., fruity), although it is debatable whether these should be classified as such.
}

between domains $\chi^{2}(1, N=919)=.239, p=.63$. Abstract words were also dominant in English speakers' responses for color, but were rare for odors. Instead source-based descriptions dominated (Fig. 1; and Table 1). This difference was statistically reliable $\chi^{2}(2, N=920)=207.72, p=.0001$.

\section{Conclusion}

Contrary to the widely-held belief that people universally struggle to describe odors, Jahai speakers name odors with ease. Whereas English speakers grappled to find words for odors, Jahai speakers could name odors with the same conciseness and level of agreement as colors. This is despite the fact that all odorants in the B-SIT were familiar 
to English speakers but not the Jahai. Many researchers have noted that English participants spontaneously generate imprecise or incorrect names for odors in free-naming tasks (e.g., Cain, 1979; Engen, 1987; Lawless \& Engen, 1977). For example, when Engen (1987) presented people with a lemon odor, people described it as air freshener, bathroom freshener, berry, magic marker, candy, citron/citrus, cleaner, Lemon-fresh Pledge, hard candy, like pine, orange, some kind of fruit, etc. We found similar responses in this study too. When the cinnamon stimulus was not labeled veridically, for example, it was called spicy, sweet, bayberry, candy, Red Hot, smoky, edible, wine, potpourri, etc. So we show, once again, that English speakers really do struggle naming smells. But the Jahai do not.

We suspect the current results underestimate the expressibility of smells in Jahai. Smell features prominently in everyday communication, as well as in the indigenous ideology and rituals of the Jahai (Burenhult \& Majid, 2011). For example, some foraged items, such as many rodent and civet species, smell $p l ? \varepsilon \eta$ to the Jahai and are considered perilous because $p l ? \varepsilon \eta$ odors attract tigers. Mushrooms, deadwood, and some types of fur and feathers are $p$ ? us - not necessarily an unpleasant smell for the Jahai. If cooked food was p?us, however, it would not be eaten since food ought to be cyos or, in the case of roasted meat or fish, crnir. In a nutshell, plants and animals are frequently described and handled in relation to their olfactory properties in the Jahai world. If we were able to sample odors that were good exemplars of these Jahai smell terms, undoubtedly codability scores would be higher.

To conclude, Jahai odor naming illustrates the dangers of extrapolating from English speakers to the rest of humanity. In order to truly explore the limits of language, people from different socio-cultural and ecological niches need to be surveyed. Jahai speakers show us that olfactory abstraction is possible, and humans can be adept at talking about smells.

\section{Acknowledgments}

This work was funded by the Max Planck Gesellschaft, the Netherlands Organization for Scientific Research grant "Human olfaction at the intersection of language, culture and biology", the Swedish Research Council (421-2007-1281), the Volkswagen Foundation (DOBES), and the European Research Council (LACOLA-263512). Thanks to the Economic Planning Unit, and JAKOA, as well as Rogayah Razak, Kobin Kendrick, Sandie Cleland, Elisabeth Norcliffe, Ewelina Wnuk, Carolyn O'Meara, Ludy Cilissen, and especially Steve Levinson.

\section{References}

Aschmann, H. P. (1946). Totonac categories of smell. Tlalocan, 2, 187-189. Berlin, B., \& Kay, P. (1969). Basic color terms: Their universality and evolution. Berkeley: University of California Press.
Brown, R. W., \& Lenneberg, E. H. (1954). A study in language and cognition. Journal of Abnormal and Social Psychology, 49(3), 454-462.

Burenhult, N., \& Majid, A. (2011). Olfaction in Aslian ideology and language. The Senses \& Society, 6(1), 19-29.

Caballero, R. (2007). Manner-of-motion verbs in wine description. Journal of Pragmatics, 39(12), 2095-2114. http://dx.doi.org/10.1016/ j.pragma.2007.07.005.

Cain, W. S. (1979). To know with the nose: Keys to odor identification. Science, 203, 467-470.

Cain, W. S., de Wijk, R., Lulejian, C., Schiet, F., \& See, L.-C. (1998). Odor identification: Perceptual and semantic dimensions. Chemical Senses, 23(3), 309-326. http://dx.doi.org/10.1093/chemse/23.3.309.

Classen, C., Howes, D., \& Synnott, A. (1994). Aroma: The cultural history of smell. London: Routledge.

Distel, H., \& Hudson, R. (2001). Judgement of odor intensity is influenced by subjects' knowledge of the odor source. Chemical Senses, 26, 247-251

Doty, R. L., Shaman, P., \& Dann, M. (1984). Development of the University of Pennsylvania smell identification test: A standardized microencapsulated test of olfactory function. Physiology $\mathcal{E}^{\prime}$ Behavior, 32(3), 489-502.

Drake, M. A., \& Civille, G. V. (2002). Flavor lexicons. Comprehensive Reviews in Food Science and Food Safety, 2, 33-40.

Engen, T. (1987). Remembering odors and their names. American Scientist, 75(5), 497-503.

Henning, H. (1916). Der Geruch. Leipzig: JA Barth.

Henrich, J., Heine, S. J., \& Norenzayan, A. (2010). The weirdest people in the world. Behavioral and Brain Sciences, 33(2), 1-75.

Hombert, J.-M. (1992). Terminologie des odeurs dans quelques langues du Gabon. Pholia, 7, 61-63.

Lawless, H. T. (1984). Flavor description of white wine by "expert" and nonexpert wine consumers. Journal of Food Science, 49(1), 120-123. http://dx.doi.org/10.1111/j.1365-2621.1984.tb13686.x.

Lawless, H., \& Engen, T. (1977). Associations to odors: Interference, mnemonics, and verbal labeling. Journal of Experimental Psychology: Human Learning and Memory, 3(1), 52-59.

Lehrer, A. (1983). Wine and conversation. Oxford: Oxford University Press.

Levinson, S. C., \& Majid, A. (in press). Differential ineffability and the senses. Mind \& Language.

Lorig, T. S. (1999). On the similarity of odor and language perception. Neuroscience \& Biobehavioral Reviews, 23, 391-398.

Majid, A., \& Levinson, S. C. (2010). WEIRD languages have misled us, too. Behavioral and Brain Sciences, 33(2-3), 103.

Majid, A., \& Levinson, S. C. (2011). The senses in language and culture. The Senses and Society, 6(1), 5-18.

Quandt, R. E. (2007). On wine bullshit: Some new software? Journal of Wine Economics, 2(02), 129-135.

Regier, T., Kay, P., \& Cook, R. S. (2005). Focal colors are universal after all. Proceedings of the national academy of sciences of the United States of America, 102(23), 8386-8391. http://dx.doi.org/10.1073/ pnas.0503281102.

Rivlin, R., \& Gravelle, K. (1984). Deciphering the senses. New York: Simon and Schuster.

Simpson, E. H. (1949). Measurement of diversity. Nature, 163, 688.

Solomon, G. E. A. (1990). Psychology of novice and expert wine talk. The American Journal of Psychology, 103(4), 495-517.

Tufvesson, S. (2011). Analogy-making in the Semai sensory world. The Senses $\quad \mathcal{O}$ Society, 6(1), 86-95. http://dx.doi.org/10.2752/ $174589311 X 12893982233876$.

van Beek, W. E. A. (1992). The dirty smith: Smell as a social frontier among the Kapsiki/Higi of North Cameroon and North-Eastern Nigeria. Africa, 62(1), 38-58.

Wilson, D. W., \& Stevenson, R. J. (2006). Learning to smell: Olfactory perception from neurobiology to behavior. Baltimore: John Hopkins University Press.

Wnuk, E., \& Majid, A. (2012). Olfaction in a hunter-gatherer society: Insights from language and culture. In N. Miyake, D. Peebles, \& R. P. Cooper (Eds.), Proceedings of the 34th annual conference of the cognitive science society (pp. 1155-1160). Austin, TX: Cognitive Science Society.

Yeshurun, Y., \& Sobel, N. (2010). An odor is not worth a thousand words: From multidimensional odors to unidimensional odor objects. Annual Review of Psychology, 61, 219-241.

Zarzo, M. (2008). Relevant psychological dimensions in the perceptual space of perfumery odors. Food Quality and Preference, 19(3), 315-322. 